\title{
Examining graphemic and lexical anglicisms in Twi for academic purposes in textbooks written in Twi
}

\author{
Osei Yaw Akoto, Charles Ofosu Marfo, Juliet Oppong-Asare Ansah, \\ Emmanuel Antwi Fordjour and Isaac Adjei Forson (Kumasi)
}

\begin{abstract}
This paper examines graphemic and lexical borrowings in Twi for Academic Purposes (TAP). Textbooks written in Asante Twi by some renowned scholars in the language constituted the dataset for this study. The textbooks were read and all instances of anglicisms or English features borrowed into Twi were collected. The borrowed-features were identified by drawing on our native speaker and scholarly competencies. The dataset was analyzed by drawing on Clyne's (1977) Borrowing Typology and Haugen's (1950) Borrowability Scale. Three key findings emerged from the analysis. First, the study yielded that in TAP two letters $(<v>$, and $<j>)$ are borrowed towards empowering Asante Twi to enable it to account for words that contain these letters. Second, at the lexical level, it was found that the borrowed words were either integrated or adapted into Asante Twi linguistic environment. The final point was that all the lexical items realized were nominals affirming the primacy of noun on borrowability scales. The findings have implications for developing Ghanaian languages for academic purposes.
\end{abstract}

\section{Introduction}

It is asserted that the "exchange of linguistic materials between two varieties of speech, mainly languages" (Capuz 1997: 81) is as old as the contact between humans from different ethnolinguistic backgrounds. Borrowing is one of the corollaries of language contact. It is defined as "the incorporation of foreign features into a group's native language by speakers of that language" (Thomason/Kaufman 1988: 37). This definition is considered more appropriate than others that limit the concept to "lexis" (e. g. Hoffer 2005; Crystal 1987). Thomason/Kaufman's (1988) use of the word "features" suggests that borrowing applies to any form of linguistic item: letter (alphabet), words, phrase, etc. Bojčić/Plavša (2012: 3) note that linguistic resources are "borrowed when there is a need to name a new object and when there is a necessity to fill in the gaps in the vocabulary of a receiving language". In a sense, borrowing is generally done for linguistic empowerment or "lexical enrichment" (Haspelmath 2008: 52) towards increasing a language's functional load.

There are two main avenues to developing the vocabulary of a language: drawing on the language's internal resources to create news words, and/or borrowing (Gramley 2001; van der Vegt 2014). The former involves such processes as clipping, compounding, blending, acronym, derivation, and affixation. The present study focuses on borrowing as a vocabulary enriching 
strategy of Asante Twi, the most widely spoken Ghanaian indigenous language (cf. Yankson 2018; Yevudey/Agbozo 2019). Studies that have investigated borrowings have looked at several domains of language use. Mutua (2013) investigated loanwords in Kikamba across ten semantic fields: transport and information technology, business, administration, health, environment and agriculture, food and clothing, religion, education, sports and recreation, and household appliances and utensils. Additionally, genres such as news broadcasting (van der Vegt 2014) have been explored. These studies overlooked the assumptions that different domains may be unique in terms of the class of words borrowed, nature of words borrowed and the processes involved in incorporating the borrowed features into the recipient language.

Studies similar to the present one in Ghana focused on Akan (which encompasses several dialects). For instance, Apenteng/Amfo (2014); Apenteng (2013); and Adomako (2008) who studied loanwords focused on Akan as though the "dialects" that constitute Akan have the same morpho-phonotactic rules and alphabetical system. This paper examines English loan-features in Asante Twi, using textbooks written in the language as the dataset. Specifically, the study seeks to find out: the graphemic borrowings; the lexical borrowings, and the part of speech of the borrowed lexical items. The present study is limited to the written domain because borrowings are highly reinforced through writing (cf. Bojčić/Plavša 2012). This principle is valid, given that writing is permanent but other modes of communication or discourse, especially speech, are transient and so influence may not last longer in the receiving language. Furthermore, the study limits itself to textbooks because they constitute the chief scholarly mode of communication in Asante Twi. It must be stated here that research articles (RAs), which are considered the chief mode of scholarly communication globally, are currently not part of the functional load of Asante Twi.

Bielenia-Grajewska (2009) asserts that linguistic influence is bi-directional, implying that a language is influenced by other languages, and also influences other languages. Thus, every language can be said to be concurrently a borrower and a lender. So while this study investigates the influence of English on Asante Twi, studies such as Bielenia-Grajewska (2009) explored the influences of other languages on English as well. It is noted that English is influenced by over eighty-four languages (cf. Bielenia-Grajewska 2009). This is geared towards the nativization of English to suit the new sociolinguistic environment (cf. Owusu-Ansah 1977). On the other hand, while English is influenced by the languages it comes into contact with, it also influences such languages - a process referred to as Englishization (cf. Boussebaa/Brown 2017).

Further, the study is limited to borrowings that are completely absorbed into Asante Twi. It means that words or expression that were used as code glosses (cf. Hyland 2005) as providing bilingual translation for the purposes of code switching or mixing were excluded. Example includes: Jdede Ens Enkyer Enne dwumadie wo Akan kasa mu, 'the use of the apostrophe in Akan'

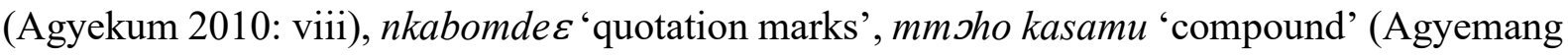
2010: viii). Agyekum (2010) provided details of some Twi terms and their English equivalence (cf. Agyekum 2010: xvii-xxiii). Such expressions are referred to as foreignisms because they are "not adapted to the recipient language's system [...]" (Haspelmath 2009: 43). 
The rest of the paper is organized as follows. A brief overview is provided on Asante Twi in Section 1.1. Section 2 discusses the theoretical framework adopted in the study. This is followed by methodology (section 3) which involves the data source and collection, and data analysis procedure, and then discussion of the findings in section 4 . Section 5 concludes the paper.

\subsection{The Asante Twi Language}

Ghana, a West African country, hosts between 45-80 local languages (Bodomo et al 2009; Dolphyne 1988; Kropp-Dakubu 2005) which belong to different branches of the Niger-Congo language family (cf. Anyidoho/Kropp-Dakubu 2008; Kropp-Dakubu 1998). The lack of consensus on the number of languages in Ghana results from the distinction between language and dialect (cf. Yankson 2018). For example, while some scholars consider Akan as a language involving dialects (e. g. Asante Twi, Kwawu, Akyem, Akuapem, Fante, and Bono) others regard "dialects" as languages in their own rights. We subscribe to the latter, considering the "lack of an operative unified orthography for the so-called Akan language group" (Abakah 2016: 10). Abakah (2016) rightly contends "we emotionally refer to Fante, Akuapem and Asante as being dialects of one and the same language. Orthographically they are separate languages". The educational curriculum in Ghana recognizes that the so-called dialects of Akan are fully fledged languages with separate syllabi and examination papers. Yevudey/Agbozo (2019) categorize the languages in Ghana into dominant and minority languages. Asante Twi, which belongs to the Kwa branch of the Niger-Congo language family, constitutes the most dominant Ghanaian local language. The dominance of the language is realized in its geographical spread, functional load, domains of use and the number of speakers. The language is used for both intra and inter-ethnic communications. It is the next lingua franca to English in Ghana.

Agyekum (2010) advocates the empowerment of Asante Twi to be used to communicate recent discourses surrounding science, technology, and computer. One of the surest ways for language growth and development is borrowing. Rubinstein (2000), for instance, remarked that American English has borrowed words from over fifty languages across the globe. Similarly, Asante Twi has borrowed, is borrowing, and will continue to borrow from some local and international languages. Rubinstein (2000) notes that "Japan borrows American words and changes their spelling and pronunciations and they become Japan words" (ibd: 23). This trend is prevalent in Asante Twi as well, but the main language borrowed from is English.

The spate of globalization and technological creations is unprecedented. Thus, Asante Twi desires to thrive to engage in global and technological and scientific communication. Borrowing is, therefore, indispensable, especially from English. This venture of Asante Twi is not uncommon as Rubinstein (2000) noted that Hebrew, having "died", had "no words for technical and technological subjects, so considerable borrowing was done from England and U. S." (ibd: 23). Asante Twi has functional loads that cut across different discourse domains. It is stated of English that "not all speakers use English for the same purpose" (van der Vegt 2014). Similarly, different categories of the Ghanaian population use Asante Twi for different purposes in the media, religion, chieftaincy, business, politics, etc. In education, Asante Twi is taught in Ghana from primary to university. Additionally, it is also used as a medium of instruction at the lower primary, according to the language in education policy of Ghana (cf. Yevudey/Agbozo 2019). In Ghana, especially in Ashanti Region and some native Twi-speaking communities, Twi is 
used as a medium of teaching and learning from crèche up to Lower Primary Three. At Upper Primary and Junior Secondary School levels, it is taught as a compulsory subject for all pupils. But at the secondary educational level, it is taught as an elective subject in the General Arts programme.

Asante Twi is also taught in higher education, that is, in almost all Colleges of Education in Ghana and public universities that offer degree programmes in Ghanaian languages. The language is, therefore, treated as a subject of study at this level of education. For example, in the University of Education, Winneba, programmes are offered in Twi Education at both undergraduate and postgraduate levels. Apart from using Twi as a pedagogic language (for teaching, learning and writing examinations) in Twi-medium courses, the language policies in some of the universities where Twi is offered makes it possible for students to write their thesis in Twi.

\section{Literature Review on Theory}

The paper investigates English borrowings in Twi for Academic Purpose. Since the beginning of interlinguistic studies, scholars have endeavoured to theorize on levels of linguistic borrowing. Scholars such as Clyne (1977) and Capuz (1997) argue that borrowing is no respecter of linguistic level. Darbelnet (1976) classified linguistic borrowing, which was later modified by Meney (1994). The two scholars based their classification on English's influence on Canadian French, and captured such levels as pronunciation; orthography and spelling; morphology, syntax, lexis, and idioms or phraseological loan translation. According to Capuz (1997), in 1974, Hunbley provided a typology of linguistic interference. Clyne (1977) proposed an octagonal model of levels of linguistic borrowing, which involved phonological, prosodic, graphemic, morphemic (transfer of bound morpheme), morphological (transfer of morphological patterns), semantic (transfer of sememes), lexical (transfer of lexemes) and syntactic (transfer of syntactic rules) borrowings. Another taxonomy of borrowing was provided by Capuz (1997) and it involves formal borrowing, morphological borrowing, semantic borrowing, lexical borrowing, syntactic borrowing, phraseological borrowing, and pragmatic borrowing. The present study adopts Clyne's (1977) typology, given that it accounts for graphemic (graphological) and lexical borrowing.

Several borrowability scales have been proposed. Matras (1998) proposed a hierarchy for coordinators: $b u t>$ or $>$ and. Meanwhile, a general scale of borrowing hierarchy was provided by Whitney (1881) (see Figure 1), which was modified and popularized by Haugen (1950).

Nouns $>$ other parts of speech $>$ suffixes $>$ inflection $>$ sounds

Figure 1: Haugen (1950) Borrowability Scale

The foregrounding of a noun is confirmed by subsequent models (e. g. Muysken 1981). But the lumping of all other parts of speech together is questionable. It suggests that there are two "parts of speech": noun and the others, which of course has no empirical or theoretical support. Interestingly, this limitation in Haugen (1950) is catered for by Muysken (1981), who provided a hierarchy of borrowing based on his analysis of Spanish borrowings in Quechua (see Figure 2). 


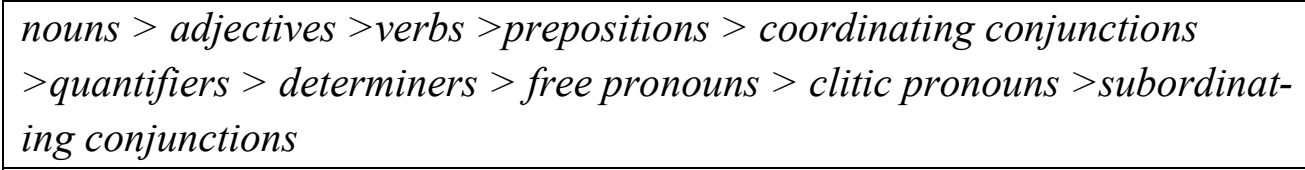

Figure 2: Muysken's (1981) Borrowability Scale

Muysken's (1981) Borrowability Scale is more detailed than Haugen's (1950) as he accounts for a number of parts of speech that were not found in Haugen (1950). Notwithstanding the strength of Muysken's (1981) model, it is difficult for some 'items' on his scale to be accepted as parts of speech (e. g. coordinating and conjunctions, quantifiers). Besides, he failed to provide a clear-cut distinction between quantifiers and determiners.

Field's (2002) also suggested a borrowability scale or borrowing hierarchy model to account for the part of speech of some borrowed words. Field (2002) proposes a similar scale for parts of speech as: content item $>$ function item $>$ agglutinating affix $>$ fusional affix. The previous ones appear more elaborate and specific than Field's (2002) hierarchy given that, for content words, the previous ones outlined each of them. Hence, the study is rooted within Muysken's (1981), borrowability scale as it accounts for some specific major and minor word classes.

Haspelmath (2008: 45) has provided four principles which attempt to justify the order of borrowings from one language into another:

a. Temporal: A language borrows elements on the left before it borrows elements further to the right.

b. Implicational: A language that contains borrowed elements from the right also contains borrowed elements further to the left.

c. Quantitative: A language borrows more elements belonging to the types on the left than elements belonging to the types to the right.

d. Probabilistic: Elements belonging to the types on the left are more likely to be borrwed(sic) than elements further to the right.

The above "principles" provided by Haspelmath (2008) are very useful as they guide in understanding the borrowability scales provided, and possibly those that will be provided in future. It should, however, be noted that his explanation may not suit all languages, and/or domains of language use such as media, religion, academia and politics.

\section{$3 \quad$ Methods and Data}

Asante Twi is used for a myriad of purposes. The present study limits itself to Academic Twi by focusing on the textbook genre. Hence, textbooks written by scholars in this language constituted the dataset for the present study. The textbooks were available at the library of Department of Ghanaian Languages, University of Cape Coast.

We read the textbooks and identified the anglicisms in them. It should be noted that if any other foreignisms other than English were found they were considered as having appeared in the language through English. The English language is said to have been influenced by over eightyfour languages (Bielenia-Grajewska 2009). Hence, such instances, except from a local language, were considered anglicisms, or an English influence. In this sense, English is perceived 
or regarded as an intermediate language (cf. Bojčić/Plavša 2012). A linguistic item was considered part of anglicism if it satisfied, at least, one of the criteria proposed by Bojčić/Plavša (2012) as follows:

a. That their original language is English.

b. That they are taken over from English.

c. That they denote objects and ideas which are of the English origin or they are integral part of the life and culture of the UK and the USA.

The analysis was carried out at two levels: graphological and lexical. The graphological analysis focused on English letters that are loaned into Twi through the borrowing of some words that contain such letters. The two languages have differences and similarities regarding the letters. So a non-Twi letter found in a borrowed word was considered a loan-letter from English. In the case of the lexical analysis, all non-Twi words were catalogued from the textbooks written in Twi. They were examined and further grouped into two categories: those that were adopted and those adapted. Finally, the classes of the borrowed items were examined. The classes of the words were ascertained by applying morphological and functional criteria. Words in this study are determined by space; however, a compound word such as poosu ffese (meaning 'post office') were counted as one.

\section{$4 \quad$ Discussion of Findings}

This section discusses the types of borrowings and the parts of speech of the borrowed words found in the Twi textbooks.

\subsection{Graphological borrowings}

The alphabets of Asante Twi and English contain twenty-two (22) and twenty-six (26) letters respectively. Those in Asante Twi are: $\langle\mathrm{a}\rangle,\langle\mathrm{b}\rangle,\langle\mathrm{d}\rangle,\langle\mathrm{e}\rangle,\langle\mathrm{\varepsilon}\rangle,\langle\mathrm{f}\rangle,\langle\mathrm{g}\rangle,\langle\mathrm{h}\rangle,\langle\mathrm{i}\rangle,\langle\mathrm{k}\rangle,<\mathrm{l}\rangle$, $<\mathrm{m}>,<\mathrm{n}>,<\mathrm{0}>,<\mathrm{j}>,<\mathrm{p}>,<\mathrm{r}>,<\mathrm{s}>,<\mathrm{t}>,<\mathrm{u}>,<\mathrm{w}>,<\mathrm{y}>$. English contains six letters which are not in Asante Twi: $\langle\mathrm{c}>,<\mathrm{j}>,\langle\mathrm{q}>,<\mathrm{v}>,<\mathrm{x}>$, and $\langle\mathrm{z}>$, while Twi also contains two letters that are not in English: $\langle\varepsilon>$ and $<\mathrm{j}>$. It can be observed that all the letters in English that cannot be found in Twi are consonants, while all those in Twi that cannot be found in English are vowels. Worthy of mention is the fact that although a grapheme may not exist in one language (i. e. neither English nor Twi), there is a way to compensate that by a phoneme, or a digraph -compound letters used to represent a phoneme.

We found two letters borrowed into the grapheme of Twi as found in the words Japanfor, televihyin/vawol. The words such as vawol ('vowel') and telsvihyin found in the data indicate that some English letters are integrated into the Asante Twi alphabet. Agyekum (2010) argues that because there are loanwords in Twi with such letters, they must be officially included in the alphabet. We think that this is long overdue and scholars on Asante Twi must be swift enough to effect this inevitable change. There are pieces of evidence in Asante Twi to support the claim that graphological borrowing is not a new phenomenon in the language. For instance, originally the Asante language did not have the consonant /1/ (described as alveolar lateral approximant) in its alphabet. This claim is supported by the fact that there is no typical Asante 
word that contains the letter $<\mathrm{l}>$. Known words in the language that contain the letter are borrowed ones such as $l \varepsilon t \varepsilon$ ('letter') and Alata ('Alata' from Nigeria). Loan-letters appear even pervasive in Asante Twi especially names. The words of the Ghana Home Page columnist, Tawiah, are deemed important here. Tawiah (2007) remarks:

I had never noticed the intrusion of the "foreign letter" $<\mathrm{c}>$ in some of our Ghanaian names, until

Seth Nketiah recently raised the issue and questioned Ghanaweb readers whether our Twi alphabet is up to standard. So Acheampong, instead of Akyeampong and Cwesi instead of Kwesi, have become fashionable. The people of Techiman have probably never realised that the letter $\langle\mathrm{c}>$ in the noun is an importation. Also, $/ \mathrm{dw} /$ in Kwadwo has also found an anglicised manifestation of $/ \mathrm{j} /$ as in Kojo. Do we have letters $<\mathrm{q}>$ and $<\mathrm{j}>$ in the Twi alphabet?

Schultz (2013) maintains that there are two ways that a language borrows letters from another language. They are direct and indirect (diphthongization) use of the exact grapheme. We see the two strategies employed to the English borrowings in Asante Twi: for direct use, the adoption of /v/ and /j/ and for indirect use /gy/ in /gyapan/. Filipović (1990), cited in Bojčić/Plavša (2012), maintained that borrowings that involve substitution are common between languages that have different morphological and phonological systems. He refers to substitution at morphological and phonological levels as transmorphemization and transphonemization respectively. Drawing on Filipović (1990), it can be argued that if languages have different graphological/alphabetic systems, letter substitution is likely to occur. This appropriately explains why in Asante Twi, an attempt is made to replace /v/ with /f/, and /j/ with /gy/.

A third strategy, which Schultz (2013) did not account for was also found in a situation where another grapheme is used in free variation with the one in the borrowed word. In the data, two different renditions of television were observed: 'tclevihyin' and 'telefihyin'. The graphemes $/ \mathrm{v} /$ and $/ \mathrm{f} /$ were used in free variation. But, sociolinguistically, it is more appropriate to use /v/. The contemporary users may desist from using /f/ in that context as it is considered a marker of "old age" and illiteracy.

\subsection{Lexical Borrowings}

In the analysis of the data, we found that lexical items borrowed from English into Twi were either adapted or adopted (Haugen 1950), and these are discussed in the ensuing subsections.

\subsubsection{Adaptation of borrowed lexical items}

Adaptation of borrowed lexical items is the process of making English conform to Twi orthography and its phonology. Accordingly, some of the loanwords found in the textbooks were completely changed to suit the graphological and phonological norms of Asante Twi. The process is also referred to as substitution such that the words undergo a norm maintaining process, to be appropriated into the Asante Twi environment. In this sense, the norms of the Asante Twi concerning the orthography and/or the phonology of the loanwords were upheld. Examples of these adapted words are as shown in Table 1. 


\begin{tabular}{cll}
\hline S/N & \multicolumn{1}{c}{ Adapted Words } & \multicolumn{1}{c}{ English forms } \\
\hline 1. & fonologyi & phonology \\
2. & mita & meter \\
3. & sentimita & centimeter \\
4. & mofim & morpheme \\
5. & setampo & stamp \\
6. & selabolo & syllable \\
\hline
\end{tabular}

Table 1: English words adapted into Asante Twi

The adaptation reality confirms the claims that borrowed words must "fit into the system of the recipient language" (Haspelmath 2009: 42) and that the forms of many donor language words are consistent with the spelling and pronunciation conventions of the target languages (van der Vegt 2014; Hoffer 2005). Appel/Muysken (1987: 152), therefore, maintain that:

[...] borrowing a word does not imply necessarily that the sounds of which the words are composed are borrowed in the same way. Of course words are phonologically adapted in the process of borrowing. What this means is that words are borrowed in a fairly abstract shape, which is then mapped on the sound pattern of the recipient language.

(Appel/Muysken 1987: 152)

It can be observed that the morpho-phonotactic rules of Asante Twi are applied to the borrowed words. From Table 1, for instance, phonology in English has been adapted to meet the norms of the new linguistic environment, hence, /fonologyi/. That is to say, the phonotactics of Asante Twi does not permit the consonant clusters /ph/, and /gy/ as word ending. Thus, /ph/ is replaced with /f/ while /gy/, a "CC" consonant cluster, is simplified as /gi/. Nativization, therefore, does not occur in phonology only (van der Vegt 2014); it also "frequently takes place through spelling" (Hock 2009: 249). Van der Vegt (2014) points that the realities on spelling and pronunciation regarding borrowing are inseparable. Hence, all the words share features on spelling and pronunciation concurrently.

\subsubsection{Imported lexical items}

Borrowed lexical items retain or contain some graphological and phonological properties of English in Asante Twi. Haspelmath (2009: 39) describes words in this category as those that contain "partly borrowed material and partly native material" and the process evoked here is described as importation/integration (Haugen 1950). We observed that there are English phonological properties "imported" into Asante Twi.

It is established that consonants do not end words or syllables in Asante Twi except where we have $/ \mathrm{m} /, / \mathrm{n} /$, and /w/ (Afoakwa 2013, 1994; Agyekum 2010). Thus, where a case like that is found in the language, it is not a typical Twi word. Thus, all the examples in Table 2 are borrowed words. 


\begin{tabular}{cclll}
\hline S/N & & Asante Twi & Asante Twi (Preferred) & Glossing \\
\hline 1. & $/ \mathrm{t} /$ & parahyut, kyokoleet & parahyutu, kyokoleeti & 'parachute, chocolate' \\
2. & $/ \mathrm{l} /$ & vawol, bool & vawolo, boolo & 'vowel, ball' \\
3. & $/ \mathrm{k} /$ & twook, klenek, Griik & twooko, kleneke, Griiki & 'chalk, clinic, Greek' \\
4. & $/ \mathrm{s} /$ & Griis & Griisi & 'Greece' \\
5. & $/ \mathrm{d} /$ & Salad & Salade & 'Salad' \\
6. & $/ \mathrm{p} /$ & Setamp & Setampo & 'Stamp' \\
\hline
\end{tabular}

Table 2: Words with borrowed English letters

Asante Twi phonology would have required that a word that ends in a consonant in English is rather ended with a vowel in the language as in the "preferred" cases indicated in Table 2. However, what we found in the books is the consonant-final case and this is a transplantation from English into Asante Twi.

More so, there are certain consonants clusters that are not permissible in Twi but the loaning has brought that into the language. Examples found in the data are $/ \mathrm{kl} /$ as in $/ \mathrm{klinik} /, / \mathrm{gl} /$ as in gluu, /nf/ as in Japanfo J. In these cases, Asante Twi is accommodating norms from the English Language (Mutua 2013). This is a way towards linguistic empowerment that enables the language to accommodate words that will require any of the processes of adaption or importation/integration (Haugen 1950). As already stated, "Japan borrows American words and changes their spelling and pronunciations and they become Japan words" (Rubinstein 2000: 23). By this practice, these words become part of the lexicon of Asante Twi, specifically Twi for Academic Purposes, as it is used for such purposes as teaching, learning, and writing of essays and thesis.

\subsection{Parts of speech of borrowed words}

Van der Vegt (2014: 27) maintains that "[...] the borrowing-induced changes are only an effect of borrowing processes but do not account for the reasons why certain words are borrowed more easily than others [...] The answer lies in the relative need for a word to fill a gap in the vocabulary of the target language". We observed from the textbooks that all the borrowed words were nouns. This affirms Haspelmath's (2008: 43) temporal principle that "a language borrows elements on the left before it borrows elements further to the right", which also support the borrowability scales (cf. Haugen 1950; Muysken 1981). In written Twi for Academic Purposes, the donor language, English, affects only the noun class. For instance, the word sulphiric, as in sulphiric acid, which is an adjective in that phrase, was nominalized in Twi as /sofe/. This could be due to the fact that morphemes are less borrowed (cf. Field 2002). Noun is part of content words, and so, in this sense, we can say that the frequency of nominal realizations confirm the borrowability scale hypothesis by Field (2002), Muysken (1981), Haugen (1950) and Whitney (1881).

More specifically, on the parts of speech, the observation that all the borrowed words are nouns is not surprising as this is common in the literature (cf. e. g. Myers-Scotton 2002; Moravcsik 1978; Whitney 1881). In fact, Haspelmath (2008: 45) contends that "it is widely acknowledged that nouns are borrowed more easily than other parts of speech". The view of the scholar and the findings of this paper are in tandem with the findings of Myers-Scotton (2002). Van Hout/ 
Muysken (1994: 42) also argued that "a very important factor involves one of the primary motivations for lexical borrowing, that is, to extend the referential potential of a language. Since reference is established primarily through nouns, these are the elements borrowed most easily". Appel and Muysken (2005) maintain that in all languages nouns account for the highest percentage of borrowing. The findings in this study contains "new and given". It is partly given because it also underscores the fact that nouns are at the apex of the borrowability scale, as confirmed by Haspelmath (2009), Appel/Muysken (2005), Van Der Sijs (2005), and MyersScotton (2002).

The noun-only borrowings in TAP is attributable to the fact that the data for the present study are limited to a written genre (i. e. textbook). It has been reported that spoken data is rich in almost all the content words (cf. Myers-Scotton 2002). However, it is quite difficult to justify why adjectives, verbs, and adverbs in written TAP are not influenced by the English language, given that all parts of speech are susceptible to borrowing (cf. van Der Sijs 2005: 57). But we can say that Asante Twi requires linguistic empowerment to communicate new scientific innovations and creations, which in themselves are nouns or names. For instance, the statement The letter was computerized will most appropriately be translated into Twi as 'Wode kompuuta boj $1 \varepsilon t \varepsilon$ '. All the verbal structures in English appear nominalized in TAP. This largely explains why verbs (and even adjectives and adverbs) are hardly borrowed into written TAP. TAP can, therefore, be said to favour nominalized structures than the other forms of the content forms. Besides, the literature on borrowing is quite silent on adjectives and adverbs. Hence, the discourse or scholarship of the "borrowability of different parts of speech" (Haspelmath 2008: 46) appears noun-centered. Almost all the studies on borrowing of other parts of speech beside nouns fall within spoken discourse (Apenteng/Amfo 2014; Adomako 2013; Quarcoo 2012).

Obviously, there is "multi-interpretability" (van der Vegt 2014: 28) to the purposes for the nouns found in the textbooks. Some are for replacement. For instance, it was observed that the word fon JlJgyi was used instead of the Twi counterpart nnyegyee $\varepsilon$. Another reason may be coexistence, given that vowel and consonant and their respective Twi counterparts - Enne nnyegyee $\varepsilon$ and anom nnyegyee - appear to be used interchangeably. But, it is highly possible that in no time the borrowed words will cause the Twi ones to be extinct (Haspelmath 2009). Both replacement and coexistence result from "non-catachrestic innovations" (Onysko/WinterFroemel 2011: 1554) or core borrowing (Haspelmath 2009). Finally, some of the occurrences may also be described as insertion, what is technically referred to as "cultural borrowing" (Haspelmath 2009) or "catachrestic innovation" (Onysko/Winter-Froemel 2011: 1554). It is said that this occurs when a phenomenon is unknown or inexistent in the recipient language. Some of those words include kreyon, telkvihyin and possibly some scientific terms such as atगm, ayगn, şfe, gaas.

\section{Conclusion}

Studies on borrowing have focused on "general data" from several semantic fields or domains of language use (cf. e. g. Mutua 2013). Departing from this supposed status quo, the present study undertook a study on borrowing in a specialized data into textbook linguistics, a branch of Language for Academic Purposes. Specifically, it explored linguistic borrowing in Twi for Academic Purposes, with a special focus on textbooks, by investigating the borrowings of 
grapheme and lexical items. At the graphological level, it was realized that Twi borrowed some letters from English. We found that all the letters that were borrowed were consonants $-<j>$ and $<\mathrm{v}>$.

TAP contains borrowed lexical items spanning across a number of academic disciplines such as Science, Computer, Technology, Chemistry, Physics, Grammar, Phonology, etc. These borrowings were done basically for the purposes of enriching the lexicon of Twi to empower it as an academic lingua franca for both old and emerging disciplines. These lexical items were either integrated/imported or adapted. The purposes for either of the strategies may be due to both linguistic and non-linguistic (Crystal 1987). Additionally, the study sought to investigate the word class of the borrowed items, which fell within the noun category.

The present study has a number of implications for Asante Twi in contemporary linguistic politics. Although English is increasingly expanding its functional load, some languages (e. g. Chinese) are also developing to rub shoulders with the world's number one language (English). It is, therefore, imperative that special attention is accorded Asante Twi and all other local Ghanaian languages to empower them as languages of contemporary discourses. This can be achieved through the efforts of academics, governments and corporate institutions. Specifically, a number of reference materials must be developed and education in such languages may be reconsidered to make them compulsory for all university students, at least, for the sophomores (first year students) in almost all the higher educational institutions in Ghana, just like the teaching and learning of Communicative Skills (also known elsewhere as English for Academic Purposes, Use of English, and Academic Writing).

The study calls for further investigations into borrowing not only in Asante Twi but also all Ghanaian languages, especially the government-sponsored ones such as Fante, Akuapem, Ewe, $\mathrm{Ga}$ and Kasem that are used as mediums of instruction at the lower primary, and studied at the higher education levels in Ghana. Further, a diachronic study can be undertaken on loanwords in Asante Twi to ascertain variations in borrowing in this language.

\section{References}

Abakah, Emmanuel Nicholas (2016): "Hypotheses on the Diachronic Development of the Akan Language Group“. Journal of Universal Language 17/1: 1-51.

Adomako, Kwasi (2008): Vowel Epenthesis and Consonant Deletion in Loanwords: A Study of Akan. Master's Thesis, University of Tromso.

Adomako, Kwasi (2013): "Underapplication in Akan loanword adaptation". International Journal of Linguistics 5/5: 174-196.

Afoakwa, Kofi A. (1994): Twi fonologyi. Kumasi: OSEYD Publishers.

Afoakwa, Kofi A. (2013): Twi kasa ho adesua bi (Orthography, grammar and translation). Kumasi: $4^{\text {th }}$ Born Printing Press.

Agyekum, Kofi (2010): Akan kasa nhyehyeec. Madina-Accra: Dwumfour Enterprise.

Anyidoho, Akosua/Kropp-Dakubu, Mary Esther (2008): “Ghana: indigenous languages, English, and an emerging national identity". In: Simpson, Andrew (ed.): Language and National Identity in Africa. Oxford, Oxford University Press: 143-56.

Apenteng, Monica Amoah (2013): A morpho-phonological study of Akan loan words. Unpublished MPhil Thesis, University of Ghana, Ghana. 
Apenteng, Monica Amoah/Amfo, Nana Aba Appiah (2014): "The form and function of English loanwords in Akan". Nordic Journal of African Studies 23/4: 219-240.

Appel, Rene/Muysken, Pieter (1987): Language contact and bilingualism. London: Edward Arnold.

Appel, Rene/Muysken, Pieter (2005): Language contact and bilingualism. Amsterdam: Amsterdam University Press.

Bielenia-Grajewska, Magdalena (2009): "Linguistic borrowing in the English language of Economics". Lexis: 107-135.

Bojčić, Ivana/Plavša, Mira Braović (2012): "Language borrowing”. Zbornik radova Međimurskog veleučilišta u Čakovcu 3/2: 1-14.

Boussebaa, Mehdi/Brown, Andrew D. (2017): "Englishization, identity regulation and imperialism”. Organization Studies 38/1: 7-29.

Gómez Capuz, Juan (1997): "Towards a typological classification of linguistic borrowing. Revista Alicantina de Estudios Ingleses 10: 81-94.

Clyne, Michael (1977): "Intercultural communication breakdown and communication conflict: Towards a linguistic model and its exemplification”. In: Molony, Carol/Zobi, Helmut/Stölting, Wilfried (eds.): German in contact with other languages. Krongberg, Scriptor: 129146.

Crystal, David (1987): The Cambridge Encyclopedia of Language. Cambridge: Cambridge University Press.

Dolphyne, Florence Abena (1988): The Akan (Twi-Fante) language: Its sound systems and tonal structure. Accra: Universities of Ghana Press.

Field, Fredric W. (2002): Linguistic borrowing in bilingual contexts. Amsterdam: Benjamins. Gramley, Stephan (2001): The vocabulary of World English. London: Arnold.

Haspelmath, Martin (2008): "Loanword typology: Steps toward a systematic cross-linguistic study of lexical borrowability". In: Stolz, Thomas/Bakker, Dik/Palomo, Rosa Salas (eds.): Aspects of language contact: New theoretical, methodological and empirical findings with special focus on Romancisation processes. Berlin, Mouton de Gruyter: 43-62.

Haspelmath, Martin (2009): "Lexical borrowing: Concepts and issues". In: Martin, Haspelmath/Uri, Tadmor (eds.): Loanwords in the World's Language: A Comparative Handbook. Berlin: Mouton de Gruyter.

Haugen, Einar (1950): “The analysis of linguistic borrowing”. Language 26/2: 201-231.

Hock, Hans Henrich (2009): Language history, language change, and language relationship: An introduction to historical and comparative linguistics. Berlin: Mouton de Gruyter.

Kropp-Dakubu, Mary Esther (2005): "The multilingual African city: Herald of the future, or vestige of colonialism”. VALS-ASLA. Bulletin Suisse de Linguistique Appliqué 82: 133-149.

Kropp-Dakubu, Mary Esther (1998): The languages of Ghana. London: Kegan Paul International (KPI) Ltd.

Matras, Yaron (1998): "Utterance modifiers and universals of grammatical borrowing". Linguistics 36/2: 281-331.

Moravcsik, Edith A. (1978): “Language Contact”. In: Greenberg, H. Joseph (ed.): Universals of Human Language. California, Stanford University Press: 93-122.

Myers-Scotton, Carol (2002): Contact linguistics: Bilingual encounters and grammatical outcomes. Oxford: Oxford University Press. 
Mutua, Ndambuki Bernard (2013): A constraint-based analysis of Kikamba nativized loanwords. Unpublished MA Thesis, Kenyatta University, Kenya.

Onysko, Alexander/Winter-Froemel, Esme (2011): "Necessary loans - luxury loans? Exploring the pragmatic dimension of borrowing". Journal of Pragmatics 43: 1550-1567.

Owusu-Ansah, Lawrence Kodwo (1997): "Nativization and the maintenance of standards in non-native varieties of English”. Kropp-Dakubu, Mary Esther (ed.): English in Ghana. Accra, Black Mask Publishers: 23-33.

Quarcoo, Millicent (2012): "Grammatical constraints on verb phrases in Twi/English Code switching”. Ghana Journal of Linguistics 1/1: 57-80.

Schultz, Julia (2013): Twentieth century borrowings from French to English: The reception and development. Newcastle: Cambridge Scholars Publishing.

Rubinstein, Marvin (2000): American English Compendium: A portable Guidebook for translators, interpreters, writers, editors, and advanced language students. Michigan: Schreiber Publishing.

Tawiah, Benjamin (2007): "Of the Twi alphabet and the letter C: A Rejoinder". ghanaweb.com/GhanaHomePage/features/Of-The-Twi-Alphabet-and-the-letter-C-A-Rejoinder117742 [11.01.2022].

Thomason, Sarah Grey/Kaufman, Terrence (1988): Language contact, creolization, and genetic linguistics. Berkeley, CA: University of California Press.

van Hout, Roeland/Muysken, Pieter (1994): "Modelling lexical borrowability". Language Variation and Change 6: 39-62.

van der Vegt, Wouter (2014): Attitudes towards English loanwords Dutch news broadcasts: The influence of gender and age. Unpublished MA Thesis, Leiden University, Netherlands.

Whitney, William Dwight (1881): "On mixture in language". Transactions of the American Philosophical Association 12: 1-26.

Yankson, Solace Ago (2018): Language contact and change in linguistically heterogeneous urban communities: The case of Akan in Accra. LOT: The Netherlands.

Yevudey, Elvis/Agbozo, Gabrial Edzordzi (2019): "Teacher trainee sociolinguistic backgrounds and attitudes to language-in-education policy in Ghana: A preliminary survey". Current Issues in Language Planning 20/4: 338-364. 